


\section{SUSTENTACIÓNTEÓRICAY DESCRIPCIÓN METODOLÓGICA DEL PROCESO DE OBTENCIÓN DE CRITERIOS DE DISEÑO Y VALIDACIÓN PARA SECUENCIAS DIDÁCTICAS BASADAS EN MODELOS: EL CASO DEL FENÓMENO DE LA FERMENTACIÓN}

\section{Theoretical framework and methodological description of the process of obtaining and validating design criteria for model-based teaching sequences: the case of the phenomenon of fermentation}

Fecha de recepción: 31 de agosto de 2014

Fecha de aprobación: 23 de noviembre de 2014

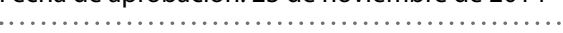

\section{Resumen}

Presentamos una forma nueva de darle cohesión al propósito, diseño y validación de secuencias didácticas en el terreno de la enseñanza de la biología, a partir del constructo 'Modelo Científico Escolar de Arribo' (MCEA). Éste está sustentado en la epistemología semanticista que enfatiza el uso de modelos científicos como forma de describir, explicary predecir los fenómenos naturales del mundoy, da pie en el ámbito de la Didáctica de la Ciencia, a la 'actividad científica escolar' -esto es a la construcción de modelos en las aulas de clase de los fenómenos estudiados por la ciencia y que presentan valor educativo-. Así mismo, destacamos el papel del MCEA como hipótesis directriz para diseñar y validar secuencias didácticas fundamentadas en modelos.

Además, presentamos una reelaboración del denominado 'rombo didáctico' que pensamos ofrece una visión más comprehensiva y heurística del quehacer didáctico; a partir de un redimensionamiento del ámbito de lo didáctico y de una interpretación del mismo en términos de modelos.

\section{López-Mota, Ángel ${ }^{1}$ \\ Moreno-Arcuri, Griselda ${ }^{2}$}

\section{Palabras clave}

Modelos, secuencias didácticas, ciencia escolar, modelo científico escolar de arribo.

\section{Abstract}

We present a new way of giving cohesion to the purpose of designing and validating teaching and learning sequences in the field of teaching biology, by offering the construct of 'School Science Arrival Model' (SSAM). This model is anchored in the semantic view of doing science and emphasizes the use of scientific models to describe, explain and predict natural phenomena with educational value and gives way to the concept of 'school science activity' -this is the construction of models in the classrooms-. At the same time, we highlight the role of SSAM as a central hypothesis to design and validate teaching and learning sequences based on models; as a theoretical-methodological reference, conceived as directive hypothesis. In addition, we show two contributions to the field: a new representation of the 'didactic rhombus' that offers a more heuristic and

1 Universidad Pedagógica Nacional. México. Correo electrónico: alopezm@upn.mx.

2 Subsecretaría de Educación Básica, Dirección General de Desarrollo Curricular. México. Correo electrónico : gmoreno@sep.gob.mx. 
comprehensive view of didactics -starting from resizing the didactic dimension- and a novel interpretation of it in terms of models.

\section{Key words}

Models, teaching and learning sequences, school science, school science arrival model.

\section{INTRODUCCIÓN}

Este artículo ${ }^{3}$ ofrece un referente teórico-metodológico llamado Modelo Científico Escolar de Arribo (MCEA)- para obtener criterios de diseño y validación de secuencias de enseñanza y aprendizaje ${ }^{4}$ fundamentadas en modelos. Esta contribución es producto del trabajo de teorización y aplicación didáctica con profesores de ciencias naturales -aquí se utiliza el caso de una investigación en el campo de la Biología- que, como parte de un programa de estudios profesionalizante de maestría ${ }^{5}$ en la Universidad Pedagógica Nacional de México, se ha venido desarrollando ya por 10 años.

Abordamos los modelos involucrados en el fenómeno de la fermentación ${ }^{6}$, cuando se diseña una secuencia didáctica. El trabajo reflexivo aquí expuesto forma parte de una serie de productos originados en una tesis de maestría (Moreno-Arcuri, 2011) e incluye otros productos académicos (Moreno-Arcuri y López-Mota, 2010a; Moreno-Arcuri y López-Mota, 2010b; Moreno-Arcuri y López-Mota, 2013).

Así, exponemos la fundamentación teórico-epistemológica, teórico-didáctica, así como la metodología inherente al diseño y validación de secuencias didácticas al amparo

3 Agradecemos la generosidad académica y humana mostrada en la revisión de este artículo, por Rufina Gutiérrez y Óscar Eugenio Tamayo.

4 En inglés: Teaching and Learning Sequences (TLS), campo de investigación y desarrollo didáctico que ya cuenta con un simposio Internacional y ha celebrado dos reuniones; una en París en el año 2000 y otro en el marco de ESERA en el año 2001 (Cfr. Méheut \& Psillos, 2004). Aquí entenderemos por TLS, las secuencias didácticas diseñadas para el aprendizaje de contenidos determinados, tomados éstos en el más amplio sentido del término. Un conjunto de 'secuencias didácticas', constituyen una 'unidad didáctica'.

5 Maestría en Desarrollo Educativo, Línea de Formación 'Educación en Ciencia'.

6 En la investigación original se trabajó con estudiantes del $1^{\circ}$ grado de educación secundaria en México, cuyas edades oscilan entre los 12- 13 años. del uso de los modelos ${ }^{7}$; señalándose las limitaciones inherentes a una fundamentación de los modelos estrictamente epistemológica. Destacamos el uso del MCEA como hipótesis directriz -fundamentada teóricamente- como elemento que permite el establecimiento de criterios para el diseño de secuencias didácticas y su validación.

De esta forma, pretendemos contribuir, con este Bioartículo-reflexión, a la deliberación sobre una forma innovadora de diseñar y validar secuencias didácticas en el terreno de la enseñanza de la Biología, fundamentada en modelos.

\section{Marco referencial}

En 2004 la revista International Journal of Science Education, dedicó un número monográfico al tema Teachinglearning sequences: aims and tools for Science Education Research, (vol. 26, número 5), del que fueron editores Martine Méheut y Dimitris Psillos. En este número, Méheut y Psillos (2004) presentan el estado de la cuestión relativa a los trabajos realizados en TLSs. Para hacer el análisis de la bibliografía revisada, utilizan categorías que representan en lo que ellos llaman "el rombo didáctico" (The didactical rhombus. Cfr p. 517).

En dicho trabajo, los autores colocan en la parte superior e inferior del rombo al 'conocimiento científico' y al 'mundo material' -dando lugar a lo que llaman la dimensión epistemológica- $y$, en la parte izquierda y derecha del mismo al 'profesor' y al 'estudiante' -dando lugar a la dimensión pedagógica-.

De esta manera, a lo largo del eje epistémico, encuentran: supuestos acerca de lo que se considera método científico, procesos de elaboración y validación del conocimiento científico, inherentes al diseño de la secuencia. En lo que respecta al eje pedagógico -que para nosotros corresponde al eje 'didáctico' como veremos más adelanteencuentran elecciones acerca del rol del profesor, tipos de interacción entre docente y alumnos, así como relación entre estudiantes. En la relación 'estudiantes' y 'mundo material' ubican las concepciones de los estudiantes sobre fenómenos científicos y, en la relación 'estudiantes' y 'conocimiento científico' colocan las actitudes hacia el conocimiento científico. De esta forma dicen, al combinar las dos dimensiones epistémica y pedagógica, les permite dar cuenta de cómo se produce el inter-juego entre

7 En este artículo se distingue entre el uso de modelos para diseñar secuencias de enseñanza y aprendizaje -así como prever su forma de validación- y el proceso de modelización seguido en clase para alcanzar los modelos previstos en el diseño. Si bien ambos están relacionados, constituyen procesos diferenciados y nosotros nos ocuparemos aquí sólo del primero. 
dimensiones en el diseño de secuencias de enseñanza y aprendizaje. Ello nos servirá para mostrar nuestra propia perspectiva acerca del diseño y validación de las mismas, tomando como ejemplo el caso de la fermentación.

El rombo didáctico de Méheut y Psillos es utilizado para 'revelar ciertas tendencias de investigación' en el campo', a partir de realizar una revisión de investigaciones en este terreno y utilizar una 'clasificación desarrollada a posteriori'. A partir de este dispositivo metodológico, fijan su atención en dos aspectos: el diseño y la validación de secuencias de enseñanza y aprendizaje.

En el asunto del diseño, ponen atención a consideraciones tales como: análisis de contenido, epistemología, concepciones de los estudiantes y sus motivaciones, aprendizaje, asuntos pedagógicos ${ }^{8}$ y constricciones educativas; lo cual realizan considerando los ejes epistemológico y pedagógico?
En lo que respecta a la validación, resaltan las posibles aproximaciones utilizadas en los trabajos revisados para abordar la validación de las secuencias. Esto lo hacen en relación con dos aspectos: 1) la medida en la cual la metodología de investigación permite evaluar la efectividad de la secuencia en relación con los objetivos previstos y, 2) el logro de las hipótesis que subyacen al diseño de las actividades en la secuencia.

\section{Nuestra perspectiva}

A continuación presentaremos nuestra perspectiva (ver Gráfico 1) en relación con el diseño y validación de secuencias de enseñanza y aprendizaje, re-conceptualizando las dimensiones epistémica y pedagógica utilizadas por Méheut y Psillos (2004), renombrando los ámbitos del conocimiento científico y mundo material dentro de un contexto escolar e introduciendo la perspectiva de modelos en una visión didáctica.

Gráfico 1

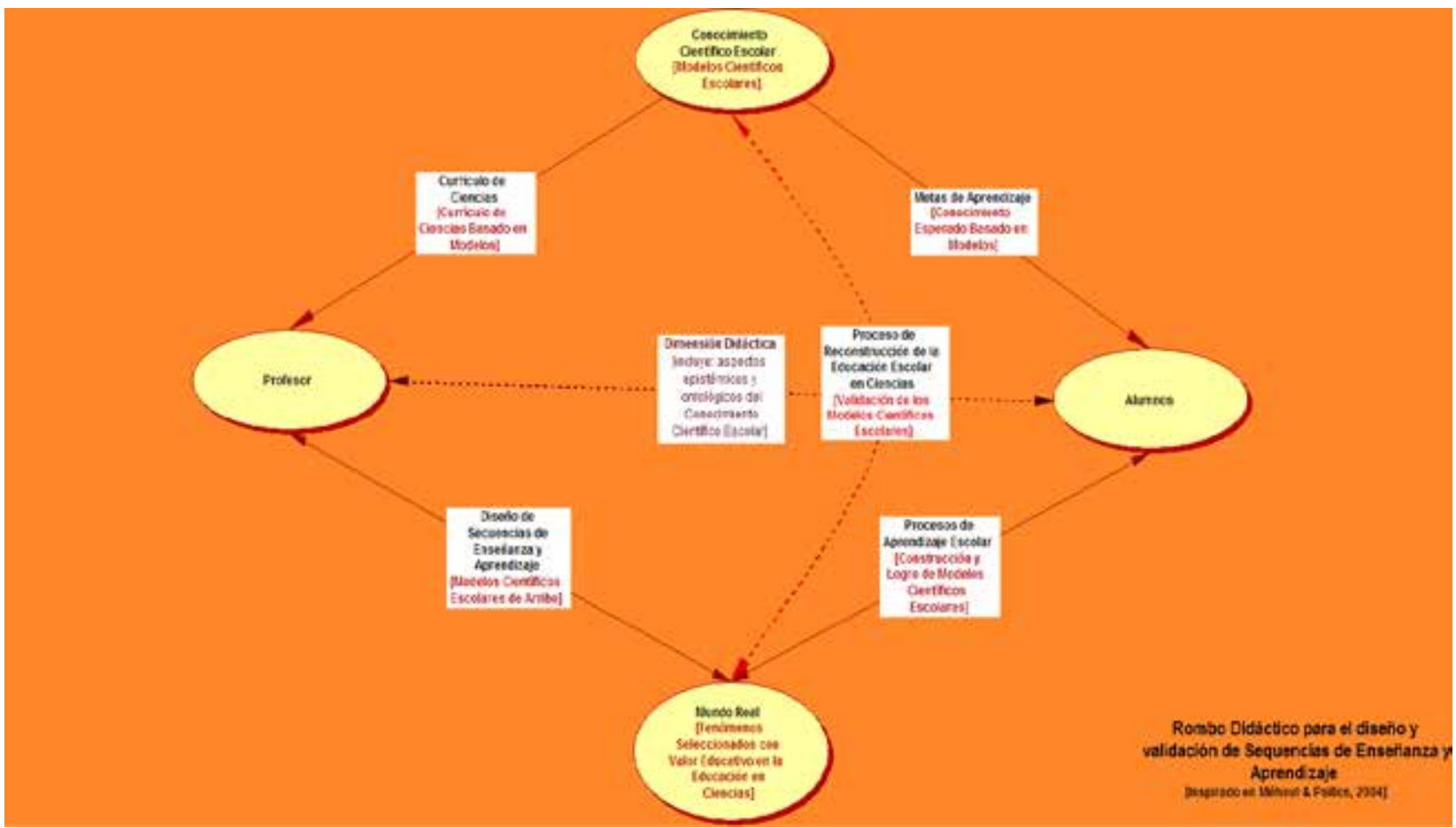

8 Para nosotros 'didácticos'.

9 De igual manera que en el pie de página anterior, es un eje 'didáctico'. 
En nuestra representación del rombo didáctico para el diseño y validación de secuencias de enseñanza y aprendizaje en ciencias, tomamos como supuesto la existencia de un campo de conocimiento científico constituido por la Didáctica de las Ciencias o Educación en Ciencias ${ }^{10}$; así como la constitución de la 'ciencia escolar' como ámbito propio -como se verá en la sección 'referente teórico'-.

La explicitación de este supuesto es fundamental para la comprensión de la naturaleza de la 'dimensión didáctica' planteada, ya que la naturaleza de tal dimensión se sustenta en la concepción del campo de la Didáctica de las Ciencias. En este sentido, ésta implica la relación profesor alumno, pero asume que el trabajo didáctico entre profesor y alumno requiere de un tratamiento educativo del conocimiento científico establecido y del mundo natural: si se trata de biología, física y química- que éste busca comprender. Por lo tanto, a diferencia del rombo didáctico de los autores mencionados, nuestra propuesta no requiere otra dimensión aparte de la didáctica; es decir que la dimensión epistemológica queda subsumida en la dimensión didáctica y a la cual nosotros hemos añadido una consideración ontológica-debido a la concepción de modelo que más adelante se presentará-.

La lectura de nuestra representación inicia en el 'conocimiento científico escolar' que - anteriormente, en el 'triángulo educativo' de Chevellard (Cfr. Izquierdo-Aymerich, 2005:112), estaba constituido por 'contenidos escolares'-, en su relación con el profesor, se manifiesta como 'currículo de ciencias' que se ofrece a éste como lineamientos para la enseñanza y contenidos científicos a desarrollar en clase. Por otro lado, el 'conocimiento científico escolar', en su conexión con los 'alumnos', se expresa como las 'metas de aprendizaje' a alcanzar.

Ahora bien, en lo que respecta a la relación entre 'profesor' y 'mundo real', ésta se manifiesta en el 'diseño de 'secuencias de enseñanza y aprendizaje' que el docente realiza para llevar a cabo su trabajo en clase. En lo relativo a la unión entre 'alumnos' y 'mundo real', ésta se expresa mediante los 'procesos de aprendizaje' -modelización si está sustentada en modelos- utilizados por los alumnos durante las sesiones de clase en las cuales se desarrollan las 'secuencias didácticas' planteadas por el docente.

10 La denominación es tomada como equivalente, sin embargo no está por demás señalar que en algunos países como España, Chile y Colombia -por citar algunos- el campo está constituido bajo el nombre de Didáctica de las Ciencias -biología, física y química-; pero que en países como México, es preferible la utilización de Educación en Ciencias, dadas las connotaciones que tiene el concepto de Didáctica, pues presenta un significado de disciplina especulativa asociada a la Pedagogía -que considera a la Didáctica de las Ciencias como un subconjunto de la Didáctica General-.
Por otra parte, en el texto, nodos y relaciones del Gráfico 1 , se encuentran entre paréntesis rectangulares las expresiones particulares -que desde el punto de vista de la incorporación de los modelos se hace del diseño de secuencias de enseñanza y aprendizaje en un contexto de Didáctica de las Ciencias y de Ciencia Escolar.

Así, nos referiremos al triángulo inferior del rombo didáctico que constituye nuestra propuesta, para abordar las cuestiones del diseño y validación de las mencionadas secuencias. En el caso de la relación 'profesor' y 'fenómenos seleccionados con valor educativo' para la Didáctica de las Ciencias o Educación en Ciencias, se manifiesta mediante la elaboración de 'modelos científicos escolares de arribo' (MCEA) -lo cual constituye un elemento esencial de nuestra propuesta y que se explicitará más adelante-. Por otra parte, en el caso de la conexión entre 'alumnos' y 'fenómenos seleccionados con valor educativo', se expresa por la 'construcción -en clase-y logro de los 'modelos científicos escolares -que también forman parte esencial de nuestra propuesta y que permite validar las 'secuencias de enseñanza y aprendizaje, al comparar los 'modelos científicos escolares de arribo' (MCEA) versus los 'modelos científicos escolares logrados' (MCEL). Esto último permitiría, en última instancia, modificar los 'conocimientos científicos escolares' -en la forma de 'modelos científicos escolares'- expresados en el 'currículo de ciencias' y en los aprendizajes pretendidos, a partir de evidencia empírica sobre su posibilidad de ser implementados en clase y alcanzados en ella.

A continuación se abordará el sustento teórico de secuencias didácticas que permitan la inclusión de aspectos epistémicos y ontológicos en nuestra perspectiva de diseño didáctico; así como del concepto de 'ciencia escolar', a partir de la concepción de modelo proveniente de la corriente semanticista en epistemología.

\section{Referente Teórico}

El referente teórico para el diseño y validación de secuencias didácticas son los modelos científicos, los cuales son pensados desde el ámbito epistemológico como representaciones mediadoras entre las teorías y los fenómenos del mundo, los cuales son retomados como esenciales en el desarrollo de la actividad científica escolar -por medio de procesos de modelización- $y$ tienen un papel primordial en el desarrollo curricular -en particular en el diseño y validación de secuencias didácticas-. De esta manera el referente teórico de los modelos presenta tres ámbitos a ser considerados: el epistemológico, el teórico-didáctico y el de las secuencias de enseñanza y aprendizaje; teniendo cada uno diferentes connotaciones. 


\section{Ámbito epistemológico}

\section{Modelo Científico desde la epistemología seman- ticista de Giere}

Aquí, no nos adentraremos en una revisión de las distintas maneras de concebir los modelos científicos desde diversas perspectivas epistemológicas, ya que no es propósito del mismo; pues de entrada nos ubicamos dentro de la corriente semanticista de R. N. Giere, en la medida en que representa ventajas para nuestra posición sobre diseño y validación de secuencias didácticas y que habrán de apreciarse cuando se aborde el MCEA como dispositivo teórico-metodológico para las mismas. Para eso está la línea de trabajo 'naturaleza de la ciencia' dentro de la Didáctica de las Ciencias de M. Izquierdo-Aymerich y A. Adúriz-Bravo (Izquierdo-Aymerich \& Adúriz-Bravo, 2003b; Izquierdo, 2007; Adúriz-Bravo e Izquierdo-Aymerich, 2009; Adúriz-Bravo, 2013); asunto que será tratado en el ámbito teórico de la didáctica y el cual aborda la pertinencia del uso de los modelos en el ámbito de la Didáctica de las Ciencias. Así mismo, estos autores se han encargado de señalar la polisemia en el uso del concepto de modelo científico, dependiendo de la perspectiva epistemológica en la que se inserten y del ámbito del conocimiento al que se refieran (Adúriz-Bravo e Izquierdo-Aymerich, 2009; Oh \& Oh, 2011; Adúriz-Bravo, 2013).

Giere es un epistemólogo interesado en argumentar a favor de los fundamentos para inclinarse sobre la naturaleza y funciones que tienen los modelos científicos-como formas de representación utilizadas por los científicospara describir, explicar y predecir el comportamiento del mundo real; dando ejemplos en el terreno de la física y la biología -aunque también es aplicable a la química-

En general, seguiremos un artículo de Giere (2004), si bien haremos también referencia a dos artículos suyos en español y otro en inglés publicados el mismo año (1999). En el artículo del 2004, empieza por enfatizar el papel que tiene el lenguaje científico como recurso para referirse a la realidad-incluidas las matemáticas, consideradas como un lenguaje- y discutir la importancia de las funciones sintácticas y semánticas del mismo. De estas dos funciones del lenguaje científico, se decanta por el abordaje de la semántica, la cual estudia la naturaleza y función de la relación entre la representación y la realidad representada; lo cual conlleva la atención hacia los referentes empíricos de lo que se busca representar y la verdad o falsedad de la hipótesis teórica en relación con éstos (Cfr. Giere, 1999a y 1999b).

Giere rescata el valor del pragmatismo a partir de reconocer que los lenguajes naturales son ante todo un logro cultural y, como dispositivo de tal naturaleza, hace a los practicantes del lenguaje, miembros de una comunidad con una cultura particular. Así, las comunidades científicas comparten este rasgo pragmático con otras comunidades que comparten el mismo lenguaje y cuyas prácticas científicas de representación de la realidad, son fundamentalmente pragmáticas. Por lo tanto, afirma, 'si deseamos entender tales prácticas, no debiéramos empezar con el estudio del lenguaje per se, sino con las prácticas científicas en el cual el lenguaje es utilizado' (Giere, 2004:743).

De esta manera, el foco de atención de Giere no se encuentra en la representación misma del lenguaje, sino en la práctica científica de la representación (Cfr. Giere, 1999b). En ella, los científicos, es decir quienes practican la representación científica, son orientados en dicha práctica por las intenciones que tienen al hacerlo. Por lo tanto, la relación que él busca impulsar en este terreno toma la forma de (Cfr. Giere, 2004):

\section{'S utiliza $X$ para representar $W$ con propósitos $P$ '}

Expresión en la cual $S$ corresponde a los científicos que utilizan diversos medios $X$ para representar ciertos rasgos del mundo real $W$ con ciertos propósitos $P$ en mente -describir, explicary predecir, principalmente-. En la práctica científica, la forma $X$ de representar el mundo real, adquiere expresiones como: palabras, ecuaciones, tablas, gráficos, fotografías, imágenes generadas por computadora, entre otras.

En la práctica científica, la manera de relacionar afirmaciones acerca del mundo y los referentes -el mundo realsobre el que se hacen afirmaciones, es realizada mediante teorías o conjuntos de teorías (Cfr. Giere, 1999b); para lo cual -esta actividad de representar el mundo real para entenderlo-, se efectúa en términos del propio Giere (1999b) de la siguiente forma:

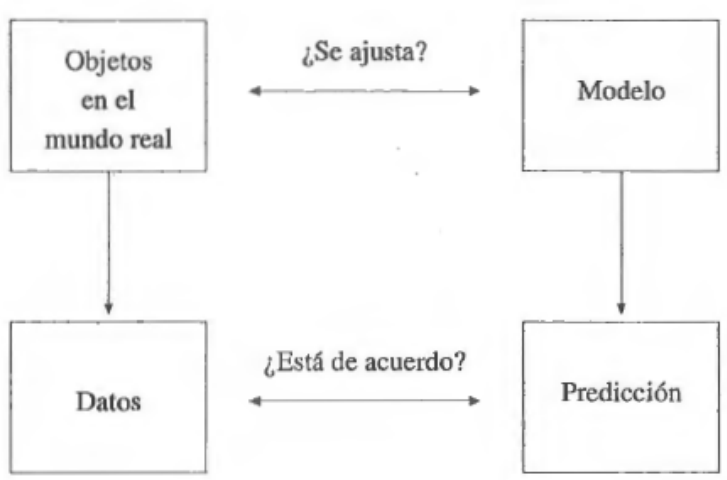

Gráfico 1 
Para Giere, la función de representar en ciencia, se ajusta mejor a las prácticas científicas, cuando se realiza bajo un entendimiento de las teorías científicas concebidas esencialmente como modelos de la realidad a representar y no como dispositivos teóricos que proveen de medios para interpretar sistemas formales (Cfr. Giere, 1999c). En estas prácticas, los científicos generan modelos mediante el uso de principios y el establecimiento de condiciones específicas de aplicación de los mismos. Al aplicar los modelos a rasgos de una porción del mundo real, se producen hipótesis que pueden ser generalizadas a una clase designada de objetos (Cfr. Giere, 1999b).

En este contexto, los principios han sido interpretados por científicos y filósofos de la ciencia -básicamente por aquellos con una visión empiricista o positivista de la ciencia-, como leyes empíricas, las cuales son consideradas como generales y verdaderas; esto es, los enunciados son de aplicación universal -sin excepciones- y corresponden punto a punto con el mundo real al cual representan. Sin embargo, Giere (1999b) tiene una visión diferente al respecto, pues para él, tales enunciados son conocidos como ciertos o falsos; pero considera que tales enunciados no debieran utilizarse para hacer reivindicaciones acerca del mundo real; sino que los principios -como genuinos enunciados- deben de contar con un referente al cual referirse y tener algo qué describir.

Acorde con esta posición de Giere, se requiere como dice él, de un objeto abstracto -que recoja rasgos esenciales del mundo real-y que por definición, este objeto posea únicamente aquellas características especificadas en los principios. Que sirva como molde o plantilla para la construcción de objetos abstractos más específicos que él llama 'modelos' y a los cuales añade condiciones específicas que los convierten en objetos abstractos con mayor grado de especificidad, pero que todavía quedan un tanto lejos del mundo real y de realizar reclamos de carácter empírico.

En la visión de las teorías científicas de Giere (2004), no hay elementos que explícitamente puedan designarse como 'La Teoría' o 'La Ley'. Ello debido a que en la práctica científica, los términos 'teoría' y 'ley' son usados de manera amplia; y dado que en la práctica científica algo es denominado 'teoría' o 'ley' -aunque funcione para él como principio-, respeta el uso de tales términos y no busca apropiárselos para su propio propósito con distinto significado.

Así mismo, en primera instancia los modelos conforman una clase heterogénea de elementos que incluye los modelos físicos, modelos a escala, modelos análogos y modelos matemáticos, por nombrar algunos. Para él, los modelos de las ciencias más avanzadas deben ser 'objetos abstractos construidos en conformidad con apropiados principios generales y condiciones específicas. Esto, de tal manera que los elementos del modelo puedan ser identificados con rasgos o características del mundo real y ello haga posible que los modelos puedan ser utilizados para representar distintos aspectos del mundo real. Los científicos realizan esta práctica con distintos propósitos y sirven de herramientas representacionales para describir, explicar y predecir el mundo que nos rodea.

\section{Ámbito teórico de la didáctica}

\section{Modelo de modelo científico en Didáctica de la Ciencias}

Una vez abordado el asunto de la función semántica de los modelos en la actividad científica para representarse el mundo y utilizar este rol para explicarlo, pasamos al ámbito del uso de los modelos en la Educación en Ciencias o Didáctica de las Ciencias. En éste encontramos que autores como Izquierdo \& Adúriz-Bravo (2003a), Izquierdo-Aymerich \& Adúriz-Bravo (2003b), Halloun (2004), Izquierdo (2007), Izquierdo y Adúriz-Bravo (2009); Adúriz-Bravo (2013) resaltan la importancia del uso de los modelos en la enseñanza ${ }^{11}$, en contraste con conceptos y leyes presentados por episodios sin ninguna relación entre ellos en el contexto de modelos apropiados para ello. Así lo deja ver el mismo Giere para el caso de libros utilizados en la educación superior para la enseñanza de la ciencia (Izquierdo y Adúriz-Bravo, 2003a:3). Si bien se ha reconocido que, desde muy recién iniciada la preocupación en el campo por el uso del 'modelo cognitivo de ciencia'12 de Giere (Izquierdo, Sanmartí y Espinet, 1999), resulta difícil establecer la conexión entre un modelo teórico y un dominio de fenómenos y se acaba por enseñar 'teoría' -esto es conceptos que no acaban por ser articulados ni usados para explicar e intervenir en el mundo-; pero, inspira una 'ciencia escolar' en donde lo más importante es enseñar a pensar con teorías vinculadas a fenómenos como consecuencia de una acción humana que utiliza su propio lenguaje (Izquierdo, 2005). Por lo que, los alumnos son privados muchas veces de la oportunidad de desarrollar una visión de la teoría científica coherente y centrada en modelos; terminando con una visión fragmentada del mundo.

11 Halloun reivindica el uso de los modelos para la enseñanza en bachillerato y Adúriz-Bravo lo hace para la educación básica.

12 Es pertinente una precisión respecto del carácter de esta denominación en el trabajo de Giere. La noción de modelo cognitivo de la ciencia es utilizada (Izquierdo-Aymerich y Adúriz-Bravo, 2003) para establecer el paralelismo y posible continuidad entre los modelos como entidades no-lingüistas en el campo de la ciencia y la cognición de los estudiantes. Sin embargo, como ellos mismos admiten, esta conexión puede ir estrictamente más allá de la estimación filosófica que él hace. 


\section{Modelo para las Ciencias Naturales}

Sin embargo, M. Izquierdo-Aymerich y A. Adúriz-Bravo (ya sea por separado o en conjunto: Izquierdo y Adúriz-Bravo, 2003a; Izquierdo-Aymerich y Adúriz-Bravo, 2003b, Izquierdo, 2007, Adúriz-Bravo e Izquierdo-Aymerich, 2009; Adúriz-Bravo, 2013), han realizado un gran esfuerzo y logrado un gran avance en argumentar la necesidad, de formular el sustento y presentar las ventajas del uso de los modelos científicos para la Educación en Ciencia, a partir de una visión 'semántica' de la ciencia la cual es la que sustenta Giere, presentada en la sección anterior-.

El origen de recuperar planteamientos epistemológicos de la corriente semanticista, para provecho de la Didáctica de la Ciencias, proviene de la intención de diseñar una auténtica 'actividad científica escolar' (Izquierdo-Aymerich y Adúriz-Bravo, 2003b) para las clases de ciencia; en donde la Didáctica de la Ciencias es una disciplina científica dedicada al diseño de una ciencia que se aprende (Izquierdo-Aymerich, 2007). Con ello, Adúriz-Bravo e Izquierdo-Aymerich (2009) buscan recuperar una concepción de los modelos científicos que resulte interesante para la enseñanza de las ciencias naturales en las aulas de primaria y secundaria. O bien, visto de otra manera, buscan identificar una postura metateórica reciente sobre la significación del término 'modelo' que tenga valor educativo y que nos sirva en la tarea de enseñar unas ciencias epistemológicamente fundamentadas (Adúriz-Bravo e Izquierdo-Aymerich, 2009).

La idea de modelo en la investigación científica, denota generalmente la idea de que se trata de una representación de una realidad compleja y de que es desarrollada con la intención de facilitar el estudio del comportamiento de la misma. Así, el énfasis es puesto en los aspectos abstractos y simbólicos del modelo, para servir de mediador entre la realidad y la comprensión teórica de la misma.

Una característica de los modelos en la que al parecer hay consenso, es que los modelos científicos son un substituto del sistema biológico, físico o químico que se encuentra en estudio. La razón es que estos sistemas, debido a su complejidad -por el número de sus componentes y lo intrincado de sus relaciones- hacen su estudio imposible. Por ello los científicos utilizan representaciones-modelos- de los sistemas que toman en cuenta sólo algunos elementos de interés para su estudio; funcionando así como mediadores entre la teoría y el mundo empírico, facilitando así el poderlos representar e intervenir en la realidad.

\section{Diferentes conceptualizaciones epistemológicas de modelo}

Hay diferentes conceptualizaciones de modelo en ciencia, dependiendo de la corriente epistemológica de la que provenga. Está por ejemplo, la concepción de modelo proveniente de una corriente lógico-positivista, que pone énfasis en la sintaxis del modelo; esto es, en que principios y leyes constituyen la teoría que busca explicar un fenómeno y que guarda una relación de correspondencia con la realidad que trata de modelar. De lo que resulta exclusiva atención en los enunciados formales que constituyen la teoría -generalmente matemáticos-y que presuponen automáticamente verdaderos y no sujetos a comprobación empírica. Hay autores que hacen una revisión de la manera de concebir los modelos desde la 'visión recibida', constituida básicamente por posiciones epistemológicas correspondientes al empirismo y positivismo -caracterizada como sintáctica y basada en la teoría-, antes de describir lo que entiende por visión 'semántica' de los modelos' (Cfr. Adúriz-Bravo, 2013).

Sin embargo, no es propósito de este artículo ahondar en ello, sino centrarnos en una concepción de modelo que prioriza la función semántica por encima de la sintáctica. Pues como lo refieren Adúriz-Bravo e Izquierdo-Aymerich (2009), lo que da sentido a la actividad científica de naturaleza teórica, es la meta epistémica que se busca alcanzar; esto es, intervenir en los fenómenos, intentar comprenderlos y aprovecharlos para mejorar las condiciones de vida de la humanidad.

Las concepciones de modelo de connotados representantes de la corriente semanticista, Suppe, Giere y van Fraassen, comparten de acuerdo con Adúriz-Bravo e Izquierdo Aymerich (2009) y Adúriz-Bravo $(2013)^{13}$, las siguientes características valiosas para la enseñanza de las ciencias naturales:

- Las teorías científicas dan significado al mundo al que se refieren y hacen sentido para sus usuarios.

- La teoría es constituida no sólo por la familia de modelos, sino también por el conjunto de sistemas empíricos para los cuales la teoría pretende dar cuenta.

- El acento epistemológico está ahora puesto en entender la naturaleza del modelo científico, más que en ubicar este dentro de una red teórica cerrada descrita mediante enunciados.

13 Si bien los listados son muy similares en ambos artículos, aquí se ha hecho una selección de ambos, de acuerdo con el propósito de ofrecer las bases de sustentación de la propuesta de diseñar y validar secuencias didácticas orientadas por modelos. 
- No hay una relación tan directa entre lo que decimos (proposiciones) y los fenómenos, sino que esa relación está mediada por los modelos.

- La teoría establece que existe una relación substantiva entre los modelos y los sistemas; al afirmar empíricamente que algunos fenómenos son adecuadamente explicados por los modelos.

\section{Modelos teóricos según la concepción semántica de la ciencia}

Para Giere - de acuerdo con Adúriz-Bravo e Izquierdo-Aymerich (2009) y Adúriz-Bravo (2013)-, el 'modelo teórico'14 se relaciona con dos elementos. Primero, con un conjunto de recursos que lo definen y segundo, el sistema del mundo que pretende modelizary con el que mantiene una relación de 'similitud'. Así, las 'hipótesis teóricas' son el vehículo del conocimiento científico que permiten realizar aserciones con contenido empírico sobre la realidad; con lo cual se puede afirmar que el modelo se parece al sistema en ciertos aspectos y grados de 'similaridad', lo que las hace susceptibles de prueba y por lo tanto corroborables o refutables de manera parcial.

\section{Modelo de modelo para actividad científica escolar}

Así, si tomamos en cuenta la caracterización anterior, de los modelos teóricos basados en la corriente semanticista de Giere, la síntesis de 'modelo teórico' para la actividad científica escolar realizada por Izquierdo (2007) y los artículos de Adúriz-Bravo e Izquierdo-Aymerich recién mencionados, da como resultado que: [un modelo] es cualquier representación-que substituye la realidad-expresada en cualquier medio simbólico, que permite pensar, hablar y actuar con rigory profundidad sobre el sistema en estudio; incluyendo maquetas, imágenes, tablas, gráficos, redes, analogías -no sólo los modelos más abstractos como los matemáticossiempre y cuando no se reduzcan a meras copias fenomenológicas del objeto representado. Sin embargo, apuntamos, que esta definición de modelo teórico o modelo científico, no está dotada de mecanismos explicativos y predictivos ${ }^{15}$-razón esencial de ser de estos modelos-.

14 Entidad abstracta, no lingüística, pero no restringida a lenguajes matemáticos.

15 Razón por la cual introduciremos más adelante la dimensión ontológica de los modelos científicos, la que da pie al establecimiento de entes y sus propiedades, relaciones entre los mismos y reglas de inferencia en el comportamiento de estas relaciones.
Como ventaja de esta manera de concebir los modelos, Adúriz-Bravo e Izquierdo (2009), argumentan que es posible reducir la carga impuesta por los formalismos matemáticos, añadiríamos nosotros- en la cotidianeidad de la ciencia escolar. Así, resulta que ya no es tan importante repetiry manipular enunciados tan sintéticos como las leyes de Newton. Sino que permitiría pensar sobre hechos considerados clave en la enseñanza de las ciencias y reconstruirlos teóricamente: caída de una manzana, balanceo de una cuerda que tiene en un extremo una pelota, la frenada de una patineta, el impacto entre dos bolas de billar. Para con ello dar sentido a los fenómenos del mundo que nos rodea: gravitación, oscilaciones, movimientos, choques, pero también fermentación, nutrición, etcétera que corresponden al mundo biológico.

\section{Modelos teóricos en la enseñanza de las ciencias naturales}

Adúriz-Bravo (2013) concibe como modelo científico escolar, el producto de un proceso de transposición didáctica, operando en el modelo científico que ha sido seleccionado para la enseñanza; lo cual dará pie en la siguiente sección al tratamiento del MCEA como herramienta teórico-metodológica en el campo del diseño y validación de secuencias de enseñanza y aprendizaje -pero fundamentada en el ámbito epistemológico, en la corriente semántica de los modelos en la ciencia-. Y describe las ventajas de utilizar la versión semántica de los Modelos Científicos Escolares, de las cuales destacamos: 1) Los Modelos Científicos Escolares pueden ser utilizados como representaciones teóricas del mundo y 2) La modelización científica escolar puede ser vista como la prueba de hipótesis sobre el grado de ajuste entre nuestras ideas y nuestras intervenciones en el mundo; ventajas que serán consideradas cuando presentemos nuestro MCEA, como hipótesis a ser validada con la implementación de una secuencia didáctica.

\section{Modelización en enseñanza de las ciencias e implica- ciones didácticas}

Modelizar o construir modelos, es una de las actividades científicas más importantes que se reconocen por filósofos de la ciencia y que ha ido ganando terreno en la Didáctica de la Ciencia (Izquierdo, 2007; y los trabajos de los dos multicitados autores). Sin embargo, la modelización -esto es, cómo 'construir modelos' es un asunto en el cual todavía hay mucho terreno por recorrer y en el que hay diversas perspectivas de lo que debería significar elaborar modelos. Nuestro artículo se propone describir la forma que nosotros hemos encontrado para orientar el diseño de secuencias didácticas y el trabajo de validar sus resultados, por medio del MCEA; pero, no es aquí nuestro propósito, ahondar en los procesos de modelización. 


\section{Ámbito de las secuencias didácticas o'teaching and learning sequences'}

\section{Uso de modelos en el diseño y validación de secuencias didácticas: Modelo Científico Escolar de Arribo (MCEA)}

Adúriz-Bravo (2013) reconoce que la implementación de la idea de modelizar en clase es muy atractiva, pero depende principalmente de la concepción de modelo que se va a poner en práctica, cuando se diseñe y ejecute cualquier actividad científica en el campo de la Didáctica de la Ciencia.

En atención a esta preocupación, es que presentamos el MCEA, que no es otra cosa sino un dispositivo teórico-metodológico ${ }^{16}$-sustentado en la visión semántica de los modelos científicos de Giere y en la conceptualización derivada de ello de 'ciencia escolar' proveniente de los planteamientos ya mencionados de Izquierdo-Aymerich y Adúriz-Bravo y en la definición aquí adoptada de modelo- que permite proceder en el diseño y validación de secuencias didácticas.

Cuando se está en la posición de diseñar y posteriormente validar una estrategia didáctica (ver Gráfico 1) fundamentada en la idea de promover en clase la construcción de modelos llevada a cabo por estudiantes, es bueno clarificar desde un inicio qué nos proponemos y hasta donde queremos llegar.

De esta manera el MCEA fue pensado con la intención de:

- Establecer el MCEA como hipótesis directriz de lo que se quiere lograr con las acciones llevadas a cabo en clase.

- Derivar criterios de diseño de la secuencia didáctica.

- Contar con criterios de validación de la secuencia didáctica.

Al diseñar una secuencia didáctica uno debe de conocer de inicio a dónde quiere llegar en términos de logro en cuanto a la construcción de modelos en clase y la elaboración del MCEA da esa oportunidad. Así, éste -en el marco de una secuencia didáctica- permite, por el proceso de validación de la misma, conformar los modelos científicos escolares que habrán de convertirse en modelos a enseñar y debieran formar parte del currículo de ciencias. En

16 En este artículo se enfatiza la parte metodológica del MCEA, pero su función teórica se manifiesta cuando se discuten los resultados obtenidos y la manera de proceder didácticamente con la definición de modelo que aquí utilizamos. este sentido un MCEA, validado en la práctica, se convierte en un modelo a ser representado por los estudiantes en clase. Y los modelos construidos por los estudiantes en clase, en modelos que tienen como referentes fenómenos de interés científico con valor educativo (Ver Gráfico 1).

Una vez establecido el MCEA - del cual se dirá más adelante la manera de elaborarlo-, de éste pueden derivarse criterios de diseño y validación de la secuencia didáctica; lo que permite otorgarle a la misma coherencia entre propósito, diseño y validación.

Ahora bien, si el propósito y el diseño se realizan en términos de modelos, es fácil rastrear su construcción durante la implementación de la secuencia didáctica en clase y podrá la misma ser validada en términos de los modelos alcanzados por los alumnos.

Pero, antes de proceder a describir la manera en cómo se obtiene el MCEA, es necesario dar cuenta del concepto de modelo manejado en nuestra propuesta; que tiene que ver con el tipo de modelo que los alumnos tienen que construir.

Sin embargo, antes de delinear la concepción de modelo científico adoptado aquí, es necesario resaltar que la descripción realizada de la postura epistemológica 'semanticista' de Giere, si bien proporciona un encuadre epistemológico sólido para pensar conceptos como 'actividad científica escolar' y construcción de 'modelos científicos escolares' como nociones fundamentales de la Didáctica de las Ciencias -postuladas por Izquierdo-Aymerich y Adúriz-Bravo y referidas aquí- presenta limitaciones:

- Prescinde de los aspectos psicológicos del aprendizaje $^{17}$. Por ejemplo, cómo y por qué construyen los sujetos (no los científicos) los modelos.

- No define claramente qué es un modelo; da sólo características generales y por ejemplo no menciona las entidades que constituyen un modelo, ni tampoco distinguen entre propiedades esenciales y otras propiedades que también tienen los modelos ${ }^{18}$.

- Da pautas limitadas para el diseño de contenidos escolares específicos ${ }^{19}$.

17 Ver nota 12 sobre precisión realizada sobre el 'concepto de 'modelo cognitivo de ciencia' de Giere.

18 Adúriz-Bravo (2013:1602) admite la necesidad de discutir la dimensión ontológica de los modelos: "Brevemente traigo aquí estas tipologías (...) porque, en mi opinión, su uso continuado en didáctica de las ciencias, requeriría una discusión anterior o simultáneo de la cuestión ontológica acerca de qué es un modelo científico" (Énfasis nuestro).

19 Ello, debido a que, por ejemplo, el modelo didáctico analógico presentado por Galagovsky y Adúriz-Bravo (2001), pretende; 
Izquierdo-Aymerich y Adúriz-Bravo (2003b:29) manifiestan la necesidad de contar con modelos científicos escolares para desarrollar la actividad científica en las aulas. Para ello, argumentan en favor de los modelos provenientes de la 'ciencia cognitiva' donde, dicen, se han desarrollado modelos cognitivos acordes con una visión semántica de las teorías -principalmente de Giere-. Sin embargo, una introducción y discusión de los modelos cognitivos -aquellos elaborados por los alumnos- en el ámbito de la ciencia escolar, requiere de un tratamiento específico para el cual no hay espacio en esta colaboración.

A partir de la obra de M. Bunge ${ }^{20}$, Gutiérrez y Pintó (2004:157, 2005: 866) han impulsado una idea general de modelo científico en términos de sus características ontológicas -independiente de un contenido disciplinar específico- y que es la que nosotros adoptamos para la elaboración del MCEA:

Un modelo científico es una representación de un sistema real o conjeturado, consistente en un conjunto de objetos con sus propiedades más sobresalientes enlistadas y un conjunto de reglas que declaran el comportamiento de dichos objetos

Esta definición de modelo ${ }^{21}$ está siendo adoptada por muchos autores en didáctica de las ciencias, aunque no todos ellos utilizan este concepto de modelo en sus

\footnotetext{
"conocer profundamente el tema que se quiere enseñar, abstraer sus conceptos nucleares y las relaciones funcionales entre dichos conceptos y traducir todo a una situación, lo más inteligible posible para el alumnado...". Pero no proporciona elementos para modelizar directamente de los fenómenos naturales en situación de experimentación; pues para ello, dentro de una epistemología moderadamente realista, se requieren elementos ontológicos para modelizar fenómenos en las aulas de clase por parte de los estudiantes.
}

20 Bunge, M. (1974-1989) Treatise on Basic Philosophy. Volumes: 1-2, Semantics; 3-4, Ontology; 5-7, Epistemology and Methodology (vol 7 with 2 parts); 8, Ethics: the good and the right (Dordrecht: Reidel Publishing) y Bunge, M., Philosophy of Physics. Reidel. Dordrecht, Holanda, 1973. Spanish trasl. by J. L. García, Filosofía de la Física. Ariel. Barcelona, 1982 (quotation from Spanish edition)

21 Rufina Gutiérrez en un artículo que aparece en este mismo volumen de la revista, afirma: "En nuestro caso, hemos optado por la ontología de Mario Bunge, por las siguientes razones: 1) Su concepción semántica de las teorías científicas [Cfr. Suppe $1974 / 1977$ ( $2^{a}$ ed.), p 223. Ver especialmente las pp 264 y ss y la 338; Una aproximación sencilla al tema del "semanticismo" en la epistemología actual puede encontrarse en Adúriz-Bravo y Izquierdo-Aymerich 2009] y 2) Su posición "moderadamente realista" (Gilbert y otros 2000) [Esta postura epistemológica es la que, en opinión de autores cualificados, parece la más adecuada para la enseñanza de las ciencias. Cfr. Ogborn 1995, Izquierdo-Aymerich y Adúriz Bravo 2003]". desarrollos curriculares (Gilbert, Pietrocola, Zylbersztajn y Franco, 2000; Cartier, Rudolph. y Stewart, 2001; Nola, 2004; Hestenes 2006; Marquez, Izquierdo, \& Espinet, 2006; Halloun, 2007; Develaki, 2007; Schwarz, Reiser, Davis, Kenyon, Achér, Fortus, Shwartz, Hug, B. and Krajcik, 2009)

Con lo anterior queda claro que el modelo teórico adoptado, tal como se ha planteado, permite orientar la planificación de la ciencia escolar; lo cual nosotros hacemos mediante el MCEA y que éste, por el proceso de validación de una secuencia didáctica, permite dar cuenta de los modelos que los alumnos son capaces de lograr en condiciones de clase y posibilita evaluar los modelos científicos escolares que se han planteado en el currículo y que derivan en lineamientos docentes para los profesores y objetivos de logro para los estudiantes (ver Gráfico 1). Así, la propuesta que nosotros hacemos en este artículo -si bien da una perspectiva global del 'rombo didáctico', se centra en la parte superior del 'rombo didáctico', la que tiene que ver con el diseño de secuencias didácticas y posibles logros de las mismas - el caso de la fermentación- mediante un proceso de validación. Lo que corresponde al logro de los modelos en clase, esto es el proceso de modelización, que ha quedado expuesto en otros trabajos (Moreno-Arcuri, López-Mota, 2010; 2013); si bien los detalles de cómo se logran los modelos, mediante las actividades didácticas en clase, no ha sido totalmente expuesto por falta de espacio en las publicaciones.

La intención del MCEA es la de alinear y hacer homogénea la información necesaria -de tres dimensiones diferentespara diseñar y validar estrategias didácticas: estudiantil -proveniente de las ideas previas de los estudiantes-, curricular -procedente de los programas de estudio- $y$, científica -originada en el ámbito científico de las distintas disciplinas-. Una vez realizada esta decisión de homogeneizar la información en términos de modelos, es necesario elaborar los modelos correspondientes de cada uno de los ámbitos señalados líneas arriba.

En el caso de los modelos iniciales de los estudiantes, esto es, aquellos que presentan los estudiantes antes de iniciar el desarrollo de la estrategia didáctica, puede ser realizado de dos maneras: mediante inferencia del modelo(s) a partir de la información de ideas previas contenida en la literatura especializada y circunscrita por edad, disciplina y tema científico de abordaje, pero también a través de la recolección de información con muestras de estudiantes con los que se va a trabajar, de los modelos presentes en ellos. 
Para hacer lo correspondiente en el ámbito curricular, hay que revisar el programa de la temática que se va a abordar, a partir de identificar un fenómeno de interés para la ciencia y presente en el abordaje curricular-en el presente caso: la fermentación - e inferir el modelo científico 'atenuado' que pudiera estar detrás de los lineamientos del programa de estudio. Esta tarea no es sencilla de realizar, ya que en muy contadas ocasiones se tienen currículos expresados en términos de modelos científicos escolares.

Por último, se revisa la literatura científica relativa al fenómeno en estudio, para identificar/seleccionar/inferir el modelo científico erudito que explica y predice el fenómeno en cuestión.

Una vez constituidos estos tres modelos, se procede a 'tensionarlos', es decir, a ponerlos en una tabla y compararlos, para postular el MCEA que servirá como criterio de diseño de la estrategia didáctica y, como herramienta de validación para probar si puede ser alcanzado o no, y en qué medida. La tensión se realiza en términos de los elementos o entidades que constituyen el sistema a ser representado, las propiedades de los mismos, las relaciones entre dichas entidades y las reglas de inferencia que rigen tales relaciones. De ahí surge el MCEA, que debe quedar ubicado en un modelo que se encuentra generalmente entre el modelo curricular y el modelo inicial de los estudiantes, pero en la línea de explicación del modelo científico.

A continuación se describe la manera de proceder para la construcción del MCEA en el caso de la fermentación. Presentamos el MCEA construido y, después, damos cuenta del MCEL; es decir aquél construido por los alumnos durante el desarrollo de la estrategia didáctica y compararlo con el MCEA.

\section{METODOLOGÍA}

\section{Homogeneización en términos de modelos: ámbitos estudiantil, curricular y científico.}

La construcción del Modelo Estudiantil Inicial (MEI) se realizó con base en la revisión y análisis de la literatura especializada acerca del fenómeno de la fermentación (Díaz, et al, 1996) y de tópicos como la respiración celular aerobia (Seymour and Longden, 1991, Cañal, 1999, Driver, et al, 2000, Charrier, et al., 2006, Tamayo y Sanmartí , 2003 y 2007, Tamayo, et al., 2008), microorganismos y descomposición de alimentos (Driver, et al., 2000; Simonneaux, 2000). Con la revisión de estos documentos, pudimos inferir que los alumnos de secundaria presentan, probablemente, el modelo presentado en la Tabla 1 (Ver Tabla 1).
El Modelo Curricular (MCu) se construyó a partir del programa de Ciencias I con énfasis en Biología (SEP, 2006) ${ }^{22}$ en el cual se pretende que los alumnos:

- Expliquen las principales diferencias entre la respiración aerobia y anaerobia relacionándolas con el tipo de organismo que las lleva a cabo ${ }^{23}$.

- Comparen las características de los organismos anaerobios y los ambientes en los que se desarrollan.

- Reconozcan la importancia de la producción de queso, pan y vino como procesos técnicos de fermentación tradicional que antecedieron el descubrimiento de la respiración anaerobia.

Con base en lo anterior, se decidió utilizar la fermentación láctica como el fenómeno con posibilidades educativas para abordar la respiración celular anaerobia. Los elementos y sus propiedades, las relaciones entre ellos, las reglas de inferencia en el comportamiento del sistema y las condiciones para que pueda aplicarse el modelo son referidos en la Tabla 1.

Al comparar ambos modelos - MEl y MCu-, encontramos diferencias entre la información obtenida de la literatura especializada -que dio lugar al MEI- acerca de la respiración y lo propuesto en el programa de Ciencias I; interpretado en términos de modelos. Las discrepancias pueden propiciar dificultades para lograr los aprendizajes esperados del programa:

- El hecho de que los individuos identifiquen como respiración, sólo la celular aerobia que utiliza oxígeno (Tamayo y Sanmartí, 2003; Cañal, 1999; Díaz, et al., 1996; Stavy, et al., 1987) y no así, la anaerobia.

- La no consideración de los microorganismos como seres vivos, por parte del estudiantado. Lo cual genera un obstáculo para identificarlos como orga-

22 Corresponde al programa oficial de estudios emitido por la Secretaría de Educación Pública en México y equivalente a los ministerios de educación de muchos países latinoamericanos.

23 Cabe mencionar que las diferencias entre la respiración celular anaerobia (ausencia de oxígeno) y la respiración celular aerobia (presencia de oxígeno), se refieren en términos de la producción de energía en forma de moléculas de ATP, así como las estructuras celulares donde se llevan a cabo, de manera tal que para la respiración celular anaerobia se producen 2 ATP por molécula de glucosa y se realiza en el citosol de la célula; mientras que, en la respiración celular aerobia, se producen 38 ATP y se lleva a cabo en la mitocondria. 
nismos que se desarrollan en ambientes carentes de oxígeno, es decir, seres vivos anaerobios.

- La atribución de factores físicos -como los cambios de temperatura- a la transformación de alimentos, ignorando la acción de los microorganismos, por lo que es difícil para los alumnos relacionar el fenómeno de la fermentación con la respiración celular anaerobia.

En lo referente al Modelo Científico (MCi) de la respiración celular anaerobia -que como efecto tiene la fermentaciónse construye a partir de la revisión de literatura especializada (Campbell, Mitchell y Reece, 2001; Campbell, Reece, 2007) acerca del proceso de respiración celular anaerobia, el resultado se presenta en la Tabla 1.

Como se observa en el MCi están presentes entidades conceptuales y relaciones (célula, glucólisis, enzimas, ácido láctico, ATP) que son construidas en la actividad científica. La relación entre éstas genera una explicación científica, en términos moleculares del fenómeno de fermentación, el cual se explica a través del modelo de respiración celular anaerobia.

En la comparación del MCu con el MCi se identifica que, para el alumno, será necesario conocer el proceso de respiración celular a nivel molecular, dado que las diferencias entre la respiración celular anaerobia y aerobia son referidas en términos del aporte de energía por cada molécula de glucosa en ausencia o presencia de oxígeno; así como la referencia a la célula y en específico al citosol -donde se realiza el proceso de glucólisis-. Desde esta perspectiva, lo que se solicita al alumno en el programa, requiere de la construcción de entidades, propiedades, relaciones y reglas de inferencia que llevan tiempo para su construcción, por el nivel de abstracción-nivel molecular-y donde la sola experimentación, no es suficiente.

\section{Tensión entre modelos y postulación del MCEA}

En la siguiente tabla se observa de manera resumida los tres modelos antes descritos:

Tabla 1. Comparación de los modelos cognitivo, curricular y científico

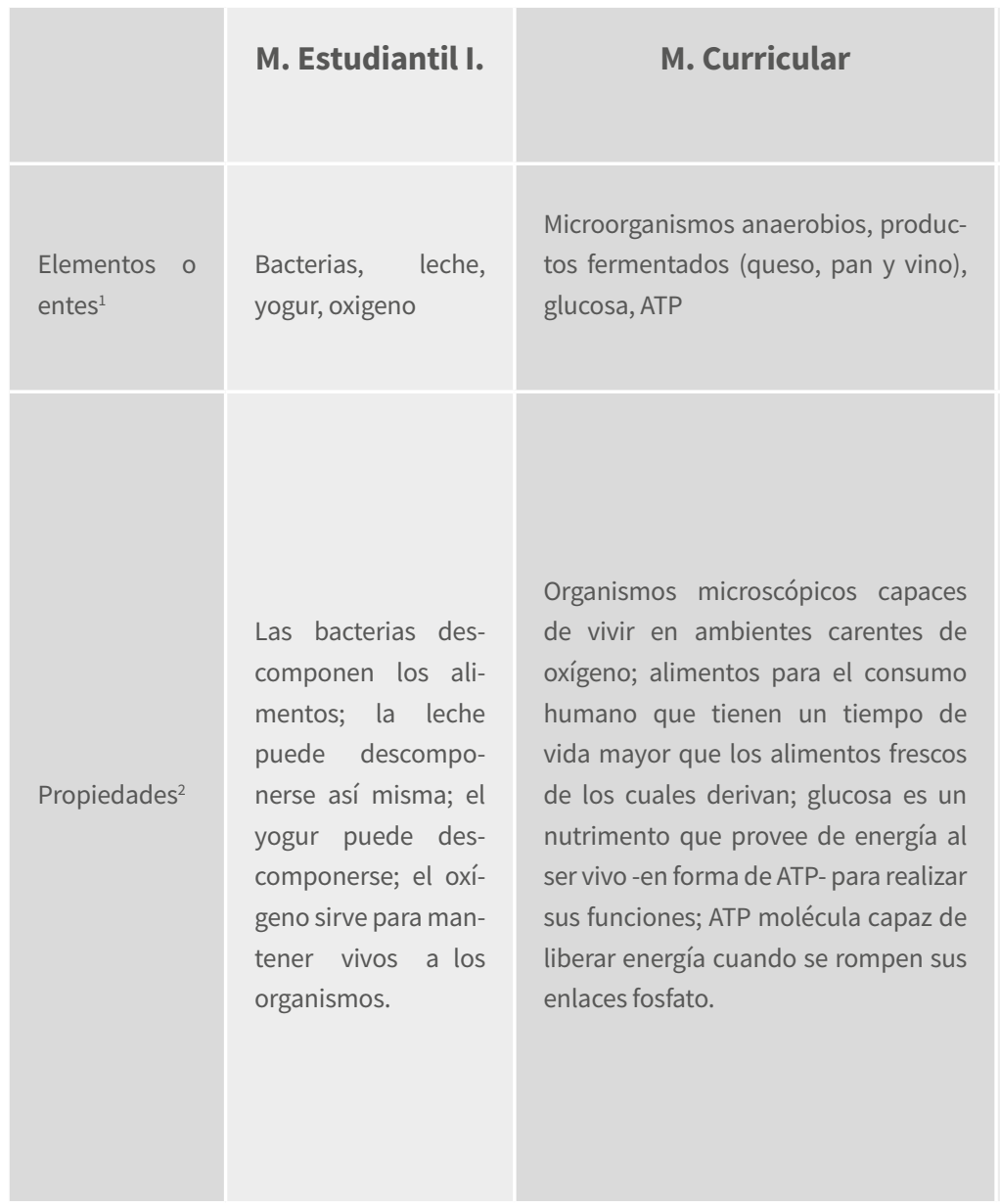

\section{Científico}

Lactobacilos, célula (citosol), enzimas, lactosa (glucosa y galactosa)

los lactobacilos son organismos unicelulares que se agrupan en colonias, poseen la enzima llamada lactasa capaz de descomponer la lactosa en glucosa y galactosa, pueden vivir en medios anaerobios, la célula es la unidad de estructura de los seres vivos que realiza la función de respiración celular para obtener energía en forma de moléculas de ATP. El citosol es la porción semifluida del citoplasma celular que favorece el desdoblamiento de la lactosa y provee de iones fosfato y de enzimas; las enzimas son catalizadores de origen proteico que aceleran o retardan la velocidad de reacción sin ser consumidas en la misma. La lactosa está conformada por glucosa y galactosa, ambos carbohidratos son fuente de energía para los seres vivos. 


\begin{tabular}{|c|c|c|c|}
\hline Relaciones $^{3}$ & $\begin{array}{l}\text { La leche es atacada } \\
\text { por las bacterias y se } \\
\text { convierte en yogur. }\end{array}$ & $\begin{array}{l}\text { Macroscópica: Las colonias de } \\
\text { microorganismos anaerobios (bac- } \\
\text { terias y hongos) se desarrollan en } \\
\text { ambientes ricos en glucosa con caren- } \\
\text { cia de oxígeno y producto de la res- } \\
\text { piración del ser vivo se producen ali- } \\
\text { mentos fermentados, por ejemplo, a } \\
\text { partir de la leche y los lactobacilos se } \\
\text { produce yogur. } \\
\text { Microscópica: Los microorganismos } \\
\text { anaerobios se desarrollan en ambien- } \\
\text { tes ricos en glucosa con carencia de } \\
\text { oxígeno. Con base en ello la glucosa es } \\
\text { transformada en compuestos de alta } \\
\text { energía (ácido láctico, etanol, ácido } \\
\text { pirúvico, ácido acético, entre otros) } \\
\text { dependiendo del alimento que se } \\
\text { trate, por ejemplo, a partir de la leche } \\
\text { los lactobacilos transforman la lactosa } \\
\text { (conformada por glucosa y galactosa) } \\
\text { en ácido láctico y se obtienen dos } \\
\text { moléculas de ATP por cada molécula } \\
\text { de glucosa y galactosa. }\end{array}$ & $\begin{array}{l}\text { Macroscópica: los lactobacilos se nutren de la } \\
\text { leche y en un ambiente carente de oxígeno, la } \\
\text { leche poco a poco va adquiriendo una consis- } \\
\text { tencia cremosa por la precipitación de proteí- } \\
\text { nas generada por el cambio de pH de la leche, } \\
\text { de } 7 \text { al inicio a } 4 \text { aproximadamente al final. } \\
\text { Microscópico: los lactobacilos para nutrirse de } \\
\text { la leche en un ambiente carente de oxígeno } \\
\text { y obtener la energía necesaria para sus fun- } \\
\text { ciones, rompen, con ayuda de la enzima lac- } \\
\text { tasa, la lactosa en glucosa y galactosa, una vez } \\
\text { obtenidos los carbohidratos, entran en el pro- } \\
\text { ceso de glucólisis que ocurre en el citosol de } \\
\text { la célula, con ayuda de diversas enzimas cada } \\
\text { molécula de glucosa y galactosa son dividi- } \\
\text { das en moléculas de ácido láctico, durante } \\
\text { este proceso hay entrada y salida de energía } \\
\text { en forma de ATP, obteniéndose como resul- } \\
\text { tado final } 2 \text { ATP por cada molécula de glucosa } \\
\text { y galactosa. El ácido láctico que se produce } \\
\text { cambia el pH de la leche y favorece la precipi- } \\
\text { tación de las proteínas lo que genera la consis- } \\
\text { tencia y olor característicos del yogur }\end{array}$ \\
\hline $\begin{array}{l}\text { Reglas de infe- } \\
\text { rencia }{ }^{4}\end{array}$ & $\begin{array}{l}\text { La descomposición } \\
\text { de la leche aumenta } \\
\text { con el calor del } \\
\text { ambiente }\end{array}$ & $\begin{array}{l}\text { Los organismos anaerobios sobrevivi- } \\
\text { rán en tanto exista suficiente glucosa } \\
\text { y sus excreciones (etanol o ácido lác- } \\
\text { tico, entre otros) no excedan un pH o } \\
\text { concentración determinada para cada } \\
\text { producto fermentado. }\end{array}$ & $\begin{array}{l}\text { Producto de la respiración celular anaero- } \\
\text { bia de los lactobacilos el medio se acidifica y } \\
\text { espesa, a mayor acidez del medio los lactoba- } \\
\text { cilos pueden morir. }\end{array}$ \\
\hline Condiciones $^{5}$ & $\begin{array}{l}\text { Ambiente caluroso, } \\
\text { medio líquido, falta } \\
\text { de aire }\end{array}$ & $\begin{array}{l}\text { Ambiente carente de oxígeno y } \\
\text { húmedo, } \mathrm{pH} \text { adecuado para el desa- } \\
\text { rrollo de los microorganismos anae- } \\
\text { robios. }\end{array}$ & $\begin{array}{l}\text { Ambiente carente de oxígeno, húmedo y } \mathrm{pH} \\
\text { ácido }\end{array}$ \\
\hline
\end{tabular}

1 "Cosa real o concreta, actual o posible” (Bunge, 2001).
2 "Rasgo o característica que posee algún objeto, ya sea conceptual o material. Todas las propiedades se conceptualizan como predicados (v.)
(atributos)" (Bunge, 2001).
3 "b] CIENCIA La mayoría de las propiedades (intrínsecas y relacionales) de las cosas reales se conceptualizan como relaciones y, en particular,
funciones" (Bunge, 2001).
4 "Prescripción para hacer algo.... Las reglas lógicas son de dos tipos: las convenciones que se ocupan de la buena formación y las reglas de
inferencia (v.). Todo sistema de lógica consiste en un conjunto de axiomas más un conjunto de reglas, sin las cuales nada puede deducirse.
Por ejemplo, el condicional "Si A, entonces B" no conduce a ninguna parte aunque se le añada que A es verdadero o B es falso. Solamente
añadiéndole la regla modus ponens (v.) se puede derivar B".
5 "b] ONTOLOGíA La causa necesaria (o contributiva) de un acontecimiento es un acontecimiento sin el cual el efecto no ocurriría” (Bunge, 2001).

Una vez que se han identificado las diferencias entre las ideas de los alumnos (MEI), lo que propone el programa de estudios ( $\mathrm{MCu}$ ) y el conocimiento científico (MCi) acerca de la respiración celular anaerobia, se identificaron los criterios básicos para construir un modelo que se fundamentara en la respiración celular anaerobia proveniente del programa de estudio, retomara las ideas de los estu- diantes, así como considerara una progresión de éstas hacia la construcción del modelo científico. Para lo anterior, se utilizó la fermentación láctica como fenómeno a modelizar, por ser un fenómeno accesible a los alumnos y con base en ello se postula el MCEA (Ver Tabla 2). 


\section{Modelo Científico Escolar de Arribo}

\begin{tabular}{|l|}
\hline Elementos \\
\hline Propiedades \\
\hline Relaciones \\
\hline Reglas de \\
\hline inferencia \\
\hline
\end{tabular}

Búlgaro (colonia de lactobacilos), leche y yogur.

Los búlgaros son bacterias que pueden vivir en ambientes carentes de oxígeno, la leche es un alimento que puede transformase por la acción de las bacterias en yogur, alimento que puede conservarse mayor tiempo que la leche fresca.

Los búlgaros al contacto con la leche se nutren de ella y como producto de la respiración de los búlgaros el pH de la leche cambia, se vuelve ácida, transformando la leche en yogur.

El pH de la leche cambia de neutro a ácido por la nutrición de las bacterias. A mayor acidez del yogur se puede provocar la muerte de los lactobacilos.

Ambiente carente de oxígeno, húmedo, pH ácido.

Tabla 2. Modelo Científico Escolar de Arribo.

Seleccionamos el fenómeno de la fermentación láctica por tres razones: 1) es un fenómeno en cierta forma "familiar" para los alumnos, el cual puede ser trabajado en la escuela sin riesgos para la salud de ellos, 2) permite evidenciar los seres vivos microscópicos como agentes de transformación de los alimentos, bajo condiciones de carencia de oxígeno, y 3) es un fenómeno propuesto por el programa de estudio de Ciencias I con énfasis en Biología (2006).

Para la integración del MCEA se procedió a identificar los elementos que están involucrados en el fenómeno de la fermentación láctica. Así tenemos: la colonia de bacterias (búlgaros) -como el ser vivo que fermenta el alimento rico en carbohidratos, en este caso la leche-, lo cual es importante porque los alumnos consideran en el $\mathrm{MEI}$, que la leche se descompone por cambios en la temperatura del ambiente o bien que se puede descomponer así misma (Díaz, et al., 1996). En este sentido incorporar la colonia de bacterias como el agente transformador de la leche en yogur, ayuda a construir la idea de que los cambios en la leche son provocados por la acción de seres vivos microscópicos, y con ello buscar explicaciones a nivel microscópico del fenómeno de la fermentación láctica.

Otra idea que se buscó construir fue evidenciar que la leche presenta cambios -no sólo en apariencia: color crema y aparición de grumos- sino en algo medible como es el grado de acidez. En este sentido, se hicieron mediciones de $\mathrm{pH}$ para tener datos de referencia, al inicio del experimento, y al final del mismo para tomarlos como evidencia y argumentar los cambios sufridos por la leche.
También buscamos que los alumnos identificaran que la transformación de leche en yogur por parte de las bacterias, beneficia a los humanos; en congruencia con el Programa de Ciencias I con énfasis en Biología (2006) y con la intención de ayudar a la construcción de la idea de que -en esta situación- las bacterias (colonia de lactobacilos) son un grupo de microorganismos que generan beneficios para los humanos, contrariamente a la idea que se tiene de las bacterias como organismos dañinos para la salud y que "echan a perder" los alimentos (Simonneaux, 2000).

Una vez decididos los elementos del modelo, se valoran las propiedades de cada uno de ellos, con especial atención en las funciones de nutrición y respiración de los seres vivos microscópicos, las cuales de acuerdo con Mondelo, García y Martínez (1994) no son consideradas por los alumnos; dado que no imaginan que estos procesos se puedan realizar en el nivel microscópico. Con base en estas propiedades se establecen las relaciones entre los elementos del MCEA, las cuales permiten tener una explicación de lo que ocurre en la fermentación láctica.

En cuanto a las reglas de inferencia, se hace hincapié en el cambio de $\mathrm{pH}$ y las repercusiones que para la colonia de bacterias tiene el aumento de acidez en el medio. Ello, con la intención de que los alumnos identifiquen que, como producto de las funciones de las bacterias, hay cambios en el medio donde se desarrollan y que tales cambios pueden alterar la vida del ser vivo, tanto que puede causarle la muerte. 
Se considera que con la elaboración del MCEA, los alumnos pueden dar cuenta del fenómeno de la fermentación láctica en términos de la nutrición y respiración de los seres vivos microscópicos; en contrapartida del MEI donde la transformación de la leche en yogur es vista como: un proceso de "descomposición" de la leche por cambios en la temperatura del ambiente, generación espontánea o bien la leche es atacada por las bacterias -quedando sin uso para los humanos-. Al mismo tiempo los alumnos pueden transitar del nivel macroscópico -al referir cambios de apariencia, colory olor de la leche- al nivel microscópico, -al señalar que los búlgaros se comen la lechey dejan residuos que cambian su consistencia, proposiciones que no observan directamente-.

\section{Formulación del MCEA como hipótesis directriz y derivación de criterios para el diseño y validación de la secuencia didáctica}

El MCEA descrito líneas arriba se constituye -con todo lo presentado anteriormente- en una hipótesis directriz a alcanzar mediante la secuencia didáctica, lo que permitirá validarla a partir de las evidencias recolectadas -en forma de información sobre modelos: elementos y sus propiedades, relaciones entre ellos y reglas de inferencia que describen el comportamiento- durante el desarrollo de la misma. Y, así, poder valorar si el MCu puede ser alcanzado o hay que modificarlo; esto es, el Modelo Científico Escolar Logrado (MCEL) permite valorar los Modelos Científicos Escolares considerados en los lineamientos curriculares y permitir su modificación con base en la investigación -como se vio en nuestra propuesta del 'rombo didáctico'-. Pero también se puede comparar con el MEI, para juzgar cuánto se transformó la manera de pensar de los estudiantes.

Así mismo, el MCEA sirve para derivar criterios de diseño de la secuencia didáctica, por lo que es posible planificar las actividades experimentales:

- Introduzcan las entidades y sus propiedades, por ejemplo, en el caso del fenómeno de la fermentación láctica es medular identificar a las bacterias (lactobacilos) como seres vivos unicelulares e individuales que pueden formar colonias (búlgaros) y vivir en ambientes con carencia de oxígeno. La leche es otra entidad con $\mathrm{pH}$ neutro el cual puede modificarse por la acción de las bacterias.

- Permitan reconocer el yogur como otra entidad, generada a partir de la relación que establecen los lactobacilos con la leche, en términos de los cambios que producen las bacterias en ésta (consistencia, $\mathrm{pH}$, color, y sabor), y qué procesos realizan aquéllas para generar esos cambios (alimentación, digestión y excreción).

- Permitan ventilar reglas de inferencia referidas a lo que podría suceder si una condición del sistema o una entidad varía su comportamiento. En el caso que nos ocupa, la fermentación láctica, se consideró el pH (condición del sistema) y con base en ello se hizo una hipótesis de lo que podría suceder con su disminución, en términos de la acidificación del sistema y su repercusión en los seres vivos (bacterias) que viven en él.

- Hacer evidentes las condiciones en las cuales se realiza las actividades experimentales. Si continuamos con el mismo ejemplo, tomamos en consideración la carencia de oxígeno (fundamental para aproximarnos a la respiración celular anaerobia), un ambiente húmedo (esencial de la respiración celular), pH ácido (resultado de la interacción de las bacterias con su medio -leche-); las que debemos tener en cuenta para que la actividad experimental a trabajar en clase nos dé los resultados que queremos lograr. Sin embargo, conviene que los alumnos experimenten con variaciones de las mismas y puedan observare inferir que sucede y, con ello, generar explicaciones en términos de la importancia de las condiciones del sistema para la sobrevivencia de las bacterias.

Conviene que las actividades experimentales permitan a los alumnos pasar de explicaciones del nivel macroscópico al nivel microscópico, donde el uso del microscopio para ampliar el sentido de la vista favorezca el desarrollo de habilidades científicas de observación, identificación y descripción. De acuerdo con Pujol (2003) la descripción adquiere mayor significado cuando los alumnos describen en términos de las relaciones entre elementos, para ello se pueden utilizar las preguntas propuestas por Izquierdo, et al (1999) ¿qué tengo?, ¿qué hice?, ¿qué paso?, las cuales están relacionadas entre sí y cuando estas son contestadas de manera coherente, las evidencias que se obtienen tienen sentido para que los alumnos se expliquen el fenómeno que están estudiando.

En cuanto a los criterios de validación de la secuencia didáctica, las evidencias a recolectar-sea de forma individual o de grupos- debe de realizarse de tal forma que aporten información sobre la construcción de modelos -con su identificación de elementos y sus características, las relaciones establecidas entre ellos y las reglas de inferencia que dan cuenta del comportamiento entre ellos. Esto con el fin de poder configurar el o los modelos 
logrados (MCEL) y poderlo(s) comparar con el MCEA y validar la secuencia didáctica.

\section{Referentes Analíticos y de logro}

Los referentes analíticos para determinar el valor de la secuencia didáctica son la postulación del MCEA y la utilización de MCEL y de MEI, con fines de comparación con el MCEA. En el primer caso comparativo, nos permite conocer lo que se puede alcanzar con la secuencia didáctica y, en el segundo, saber la modificación realizada al modelo inicial de los estudiantes.

En la comparación del Modelo Científico Escolar Logrado (MCEL) -inferido a partir de las evidencias colectadas durante la implementación de la secuencia didáctica por los alumnos en clase (reportados en Moreno-Arcuri y López y Mota, 2013) y el MCEA, pudimos advertir que el estudiantado logra identificar que los lactobacilos son los responsables de la transformación de la leche en yogur. Esta conclusión es importante en dos sentidos: 1) La atribución de la transformación de la leche a un ser vivo, dado que Díaz, et al. (1994) reporta que la mayoría de los alumnos atribuye los cambios en los alimentos a factores físicos y químicos, y no así a seres vivos; 2) El hecho de considerar la transformación del alimento (leche) como un antecedente para la introducción del concepto energía; si ésta se entiende como la capacidad de los sistemas para generar transformaciones (Furió-Gómez, Solbes y Furió-Mas, 2007).

Es importante mencionar que, a partir de la construcción de los modelos científicos escolares, se favoreció la conversación entre los alumnos del grupo, lo que permitió destacar los procesos que realizan los microorganismos y cómo estos transforman el medio donde viven. Sin embargo, cabe mencionar que, la mayoría de los escolares, refieren las transformaciones a nivel macroscópico y no logran relacionarlas con lo que sucede a nivel microscópico.

En lo referente a identificar que algunos seres vivos microscópicos respiran en ausencia de oxígeno, consideramos que es necesario trabajar el modelo 'ser vivo-célula' (Gómez, 2007). Ello se hace evidente porque los alumnos no identifican a las bacterias (Lactobacilos sp.) como individuos propios sino como fragmentos del búlgaro. Por tanto, denota la dificultad que enfrenta el estudiantado al no concebir la vida a escala microscópica dado que esta idea choca con su experiencia basada en el nivel macroscópico; en el cual muchos de los seres vivos que conocen los alumnos respiran mediante pulmones.
En la comparación del Modelo Científico Escolar Logrado (MCEL) por lo alumnos y el MEI -es decir su modelo inicial inferido-se puede decir que los alumnos identifican la existencia de seres vivos que producen transformaciones en la leche a partir de la función de nutrición; lo cual representa un avance, puesto que la literatura (Díaz, et al., 1996) reporta que los alumnos tienen la idea de que los cambios en la leche son consecuencia de factores físicos y por generación espontánea. Sin embargo, los alumnos no identifican las bacterias como los seres vivos microscópicos responsables de la transformación de la leche en yogur. Identifican a la colonia y ello tendría que considerarse en estrategias didácticas posteriores e incluir actividades tendientes a identificar que el búlgaro es una colonia de bacterias.

\section{CONCLUSIONES}

La introducción del MCEA en el diseño y validación de secuencias didácticas en el campo de la biología, teniendo como ejemplo el fenómeno de la fermentación, permite:

- Disponer de un dispositivo teórico-metodológico (MCEA) que permite construir criterios de diseño específicos para elaborar y validar secuencias didácticas en términos de modelos; acorde con una visión sustentada y pertinente de 'actividad escolar' propuesta en el campo de Didáctica de las Ciencias, que permite otorgar coherencia al propósito, diseño y validación de secuencias didácticas.

- Contar con una hipótesis directriz (MCEA) como medio de validación que, sustentada teóricamente, permita validar la secuencia didáctica en términos de lo que se propuso lograr y, al mismo tiempo, evidenciar la efectividad de la misma -al conocer lo distanciado de los modelos construidos en clase (MCEL) respecto de lo pretendido al diseñar la secuencia didáctica-.

- Contrastar lo planeado -MCEA- con lo logrado en clase-MCEL-y validar con datos empíricos de investigación en aula, lo que es posible alcanzar; ayudando a reformular los 'aprendizajes esperados' contenidos en los lineamientos curriculares.

- Contar con criterios para introducir entes o entidades, propiedades de éstos, relaciones entre los mismos y reglas de inferencia en el comportamiento del sistema modelado, para sugerir momentos de introducción y tipo de actividades durante el curso de la secuencia didáctica -en este caso de la fermentación-. 
- Considerar articuladamente los ámbitos: estudiantil, curricular y científico y derivar de ello una herramienta metodológica (MCEA) que oriente la planificación de actividades experimentales que favorezcan 'la actividad científica escolar'.

\section{Referencias}

Adúriz-Bravo, A., 2013, A 'Semantic' View of Scientific Models for Science Education. Science \& Education, $22(10), 1593-1611$

Adúriz-Bravo, A. e Izquierdo-Aymerich, M. (2009). “Un modelo de modelo científico para la enseñanza de las ciencias naturales", Revista Electrónica de Investigación en Educación en Ciencias. Vol. 4, núm. 1, febrero, 2009, pp. 40-49ISSN (Versión electrónica): 1850-6666.

Bunge, M. (2001). Diccionario de Filosofía. México: Siglo XXI Editores, pp. 219.

Cartier, J., Rudolph, J. y Stewart, J., 2001, The nature and structure of scientific models. Available on line: <http://www.wcer.wisc.edu/ncisla> [Agosto 2014].

Charrier, M., Cañal, P., Rodrigo, M. (2006). Las concepciones de los estudiantes sobre la fotosíntesis y la respiración: una revisión sobre la investigación didáctica en el campo de la enseñanza y el aprendizaje de la nutrición de las plantas. Enseñanza de las ciencias, 24 (3), 401-410.

Campbell, N., Mitchell, L. y Reece, J. (2001). Biology: Concepts and Connections. San Francisco: Addison Wesley Longman, Inc. Third Ed. v.e. Campbell, N., Mitchell. L. y Reece, J. (2001). Biología: Conceptos y relaciones. México: Pearson/Educación. 3a. edición.

Develaki, M, 2007, The Model-Based View of Scientific Theories and the Structuring of School Science Programmes. Science \& Education, 22, 1613-1632.

Díaz, R., López, R., García, A., Abuín, G., Nogueira, E. y Gandoy, J. (1996). ¿Son los alumnos capaces de atribuir a los microorganismos algunas transformaciones de los alimentos? Enseñanza de las ciencias, 14 (2), 143-153.

Furió-Gómez, Solbes, J. y C. Furió-Más, (2007). Historia del primer principio de la termodinámica y sus implicaciones didácticas. Rev. Eureka Ensen. Divul. Cien., 4 (3), 461-475.
Galagovsky, L. y Adúriz-Bravo, A. (2001) Modelos y analogías en la enseñanza de las Ciencias Naturales. El concepto de modelo didáctico analógico. Enseñanza de las Ciencias, 19 (2), 231-242.

Gilbert, J. K., Pietrocola, M., Zylbersztajn y Franco, C., 2000, Science Education: Notions of Reality, Theory and Models. En: Gilbert, J. K. y Boulter, C. J. (eds), Developing models in Science Education. Kluwer. Dordrecht, The Netherlands, p 19-40.

Giere, R. N. (1999a). "Del Realismo Constructivo al Realismo Perspectivo", Enseñanza de las Ciencias (Núm. Extra), pp. 9-13.

Giere, R. N. (1999b). "Un Nuevo Marco para Enseñar el Razonamiento Científico" Enseñanza de las Ciencias (Núm. Extra), pp. 63-70.

Giere, R. N. (1999c). “Using Models to Represent Reality”. In Model-Based Reasoning in Scientific Discovery, Ed. L. Magnani, N. J. Nersessian, and P. Thagard, 41-57. New York: Kluwer/Plenum, 1999 (26 julio 2014: http://www.tc.umn.edu/ giere/R\&Fpubs.html).

Giere, R. N. (2004). "How Models are Used to Represent Reality”, Philosophy of Science, 71 (December 2004) pp. 742-752.

Gómez, A. (2007). Fundamentación teórica y diseño de una unidad didáctica para la enseñanza del modelo ser vivo en la escuela. Enseñanza de las Ciencias, 25 (3), 325-340.

Gutiérrez, R. (2001). Mental models and the fine structure of conceptual change. A Pintó, R. i Suriñach, S. (Eds.) Physics Teacher Education Beyond 2000, Paris: Elsevier, p. 35-44.

Gutierrez, R. and Pinto, R. (2004), Models and Simulations. Construction of a Theoretically Grounded Analitic Instrument. En: Mechlová(ed), Proceedings: Teaching and Learning Physics in New Contexts. Selected Papers. GIREP 2004 International Conference. University of Ostrava. Ostrava, Czech Republic. p 157-158. (ISBN 80-7042-378-1) (https://www.girep. org/proceedings/conference2004/Rufina_Gutierrez_ Models_andSimulations._Construction_of_a_ Theoretically_Grounded_Analytic_Instrument.pd).

Halloun, I. A. (2004). Modelling Theory in Science Education. The Netherlands: Kluwer Academic Publishers, $250 \mathrm{pp}$.

Halloun, I. A., 2007, Mediated Modeling in Science Education. Science \& Education, 16, 653-697. 
Hestenes, D., 2006. Notes for a Modeling Theory of Science, Cognition and Instruction. In: E. van der Berg, A. L. Ellermeijer, O. Sloote (eds), Proceedings of the GIREP 2006 International Conference on "Modeling in Physics and Physics Education". Univ. of Amsterdam (The Netherlands), p 34-65.

Izquierdo, M. (2005). "Hacia una teoría de los contenidos escolares”, Enseñanza de las Ciencias 23(1), 111-122.

Izquierdo-Aymerich, M. (2007). "Enseñar ciencias, una nueva ciencia”. Enseñanza de las Ciencias Sociales, 6, 125-138.

Izquierdo, M. Sanmartí, N. y Espinet, M. (1999). Fundamentación y diseño de las prácticas escolares de ciencias experimentales. Enseñanza de las Ciencias, 17(1), 45-59.

Izquierdo, M., Adúriz-Bravo, A. (2003a). "Contributions of the Cognitive Model of Science to the Didactics of Science", Sixth IHPST Conference, William Mc Comas, ed, 065 (12 pags).

Izquierdo-Aymerich, M. \& Adúriz-Bravo, A. (2003). "Epistemological Foundations of School Science", Science \& Education 12: 27-43, 2003.

López-Mota, A. y Rodríguez-Pineda, D. (2013). “Anclaje de los modelos y la modelización científica en estrategias didácticas", Enseñanza de las Ciencias, Núm. Ext. IX Congreso Internacional sobre Investigación en Didáctica de las Ciencias, pp. 2008-2013.

Marquez, C., Izquierdo, M., \& Espinet, M. (2006). Multimodal science teachers' discourse in modeling the water cycle. Science Education, 90 (2), 202-226.

Méheut, M. \& Psyllos, D. (2004). "Teaching and learning sequences: aims and tools for science education research", Int. J. Scie. Edu. Vol. 26, No. 5, 515-655.

Mondelo, A., García, S. y Martínez, C. (1994). Materia inerte/Materia viva. ¿Tienen ambas la misma constitución atómica? Enseñanza de las ciencias, 12(2), 226-233.

Moreno-Arcuri, G. (2011). Construcción de modelos escolares, en un grupo de primero de secundaria, acerca de la fermentación. Tesis de Maestría, México: Universidad Pedagógica Nacional.

Moreno-Arcuri, G. y López-Mota, A. (2010a). "Problemas de modelización estudiantil presentados en el desarrollo de una estrategia didáctica sobre respiración anaeróbica, utilizando la fermentación láctica". En: López-Mota, A. et al. (coords.). La investigación en el posgrado de la Universidad Pedagógica Nacional (pp. 139-153). UPN.
Moreno-Arcuri, G. y López-Mota, A. (2010b). "Estrategia didáctica para promover en alumnos de primero de secundaria la construcción de un modelo intermedio de respiración anaerobia cercano al modelo científico", Ponencia: IX Convención Nacional y II Internacional de Profesores de Ciencias Naturales San Francisco de Campeche, Campeche, del 11 al 14 de Noviembre.

Moreno-Arcuri, Griselda y López-Mota, Ángel D. (2013). "Construcción de modelos en clase acerca del fenómeno de la fermentación, con alumnos de educación secundaria". Revista Latinoamericana de Estudios Educativos. No. 1, Vol. 9, pp. 53-78. Manizales: Universidad de Caldas.

Nola, R., 2004, Pendula, Models, Constructivism and Reality. Science \& Education, 13, 349-377.

Phil Seok Oh \& Sung Jin Oh (2011) What Teachers of Science Need to Know about Models: An overview, International Journal of Science Education, 33:8, 1109-1130, DOI: 10.1080/09500693.2010.502191.

Pujol, R. M. (2003). Didáctica de las ciencias en la educación primaria. Madrid: Síntesis.

Secretaría de Educación Pública (2006). Educación Básica. Secundaria. Ciencias. Programas de estudio 2006. México: SEP.

Seymor, J. and Longden, B. (1991). Respiration -that's breathing isn't it? Journal of Biological Education, 25(3), 177-183.

Simonneaux, L. (2000). A study of pupil's conceptions and reasoning in connection with 'microbes', as a contribution to research in biotechnology education. International Journal of Science Education, 22(6), 619-644.

Schwarz, C. V., Reiser, B. J., Davis, E. A., Kenyon, E., Achér, A., Fortus, D., Shwartz, Y., Hug, B. and Krajcik, J., 2009. Developing a Learning Progression for Scientific Modeling: Making Scientific Modeling Accessible and Meaningful for Learners. J. of Res. in Science Teaching, 46 (6), 632-654.

Tamayo, O., Orrego, M., Dávila, A. (2008). Modelos explicativos del concepto de respiración. Memorias CIIEC 2008, 2(3), 50-63. 